\title{
Experimenting with New Crops at the Peri-Urban Fringe
}

\author{
Fissore Cinzia ${ }^{1 *}$ and Zappia Natale ${ }^{2}$ \\ ${ }^{1}$ Department of Biology and Environmental Science, Whittier College, USA \\ ${ }^{2}$ Department of History and Environmental Studies, Whittier College, USA
}

*Corresponding author: Fissore Cinzia, Department of Biology and Environmental Science, Whittier College, USA

\section{Farming at the Peri-Urban Fringe}

As the world's human population increases, so too does the demand for food and fibers. However, our ability to meet such demand is challenged by the decline in high quality farmland due to soil degradation, de-agrarianisation and the expansion of urban development [1]. The peri-urban fringe the transition area where rural and urban features and functions intersect and coexist [2]. experiences unique economic, social, and environmental changes [3].The peri-urban fringe is an area of substantial ecological pressure in relation to space, frequently characterized by land fragmentation, loss of prime agricultural space, and resulting decline in biodiversity [4]. Conversely, as a socio-economic space of great ecological value, it can be seen as a place of opportunities, where human and natural systems co-exist and resulting ecosystem services become strongly linked to anthropogenic practices and decisions. For example, a dynamic and integrative approach to farming-multifunctional agriculture-emerges at the peri-urban fringes and points to a promising new array of both ecosystem services and socio-cultural benefits reimagining older, more entrenched methods of food production [5]. Notably, many commercial farmers only marginally understand the complex set of relationships linking farmland and residential land use despite the enormous potential for profitability, ecological sustainability, novel socio-cultural connections, and food justice resolution.
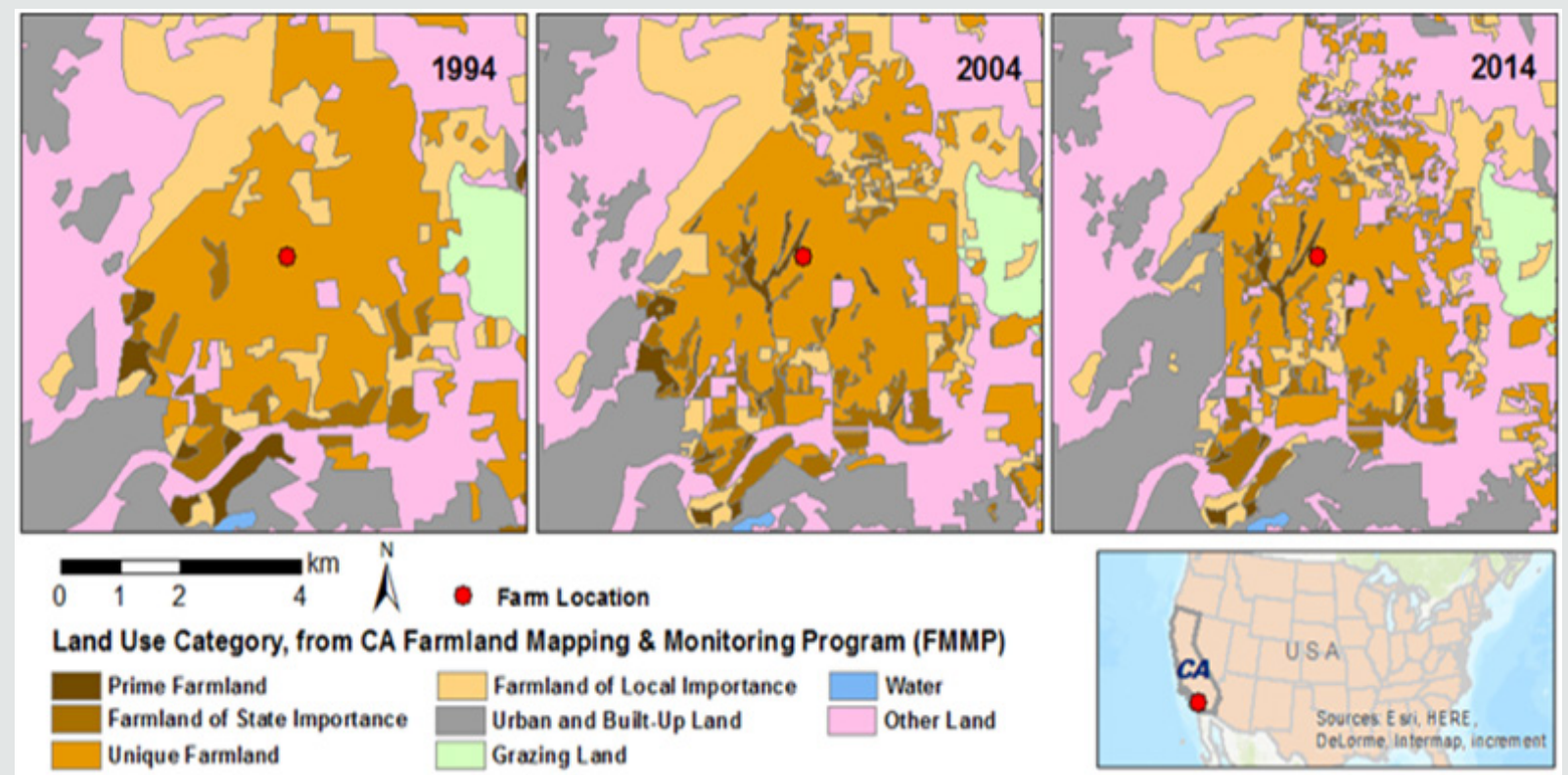

Figure 1: Land use change in the period 1994 - 2014 showing pressure of urban development on agricultural land. The red dot in each panel indicates one of the farms in San Diego Co. that has experimented with coffee-avocado intercropping.

Ranked \#1 in U.S. crop production and accounting for over $12 \%$ of the U.S. population [6,7]. the state of California (CA), serves as a prime example of the challenge described above. The state has long provided a significant proportion of the fruits and nuts consumed 
in the U.S., and it alone accounts for $86 \%$ of national avocado production. Demographic pressure is at the root cause of CA's rapid land use change. Recent census data indicate that in the period from 1990 to $2000 \mathrm{CE}$ alone, over 10 million housing units were added in the state, highlighting the trend of sustained urban growth (Figure 1). Estimates suggest that, by 2050, over 12 million acres of farmed land or rangeland will be lost to development in CA [4]. According to recent data (FMMP; www.conservation.ca.gov), prime irrigated farmland characterized by high soil quality and large contribution to the food market-has been the most vulnerable of all agricultural land to urbanization, likely due to the fact that a large portion of this fertile land is located in the proximity of developed areas [8]. Land loss to residential development threatens the longterm sustainability and profitability of CA's tree crop agriculture, but so too does the ongoing drought and future impacts of climate change. Improving soil health by building soil organic carbon (SOC) in these agricultural systems can act as critical tools to increase resilience to drought and offset greenhouse gas (GHG) emissions. If adopted with limited water application, intercropping-the practice of simultaneously growing two crops on the same land [9]. can represent an ecologically and financially valuable solution to issues pertaining to food sourcing and resource use. Intercropping boosts productivity, increases SOC, and enhances nutrient and water retention [10].

\section{The Case for California Grown Coffee}

A newcomer to Southern California, coffee represents a niche cultivar. Faced with extreme competition, some growers have innovated by introducing an alternative additional crop to existing high value production systems to remain successful and economically viable without expanding their footprint. Coffee and avocado growers are thus poised to lead a new transformation in the CA foodscape-indeed a new agricultural boom that relies on sustainable organic food production. In the past decade, approximately thirty producers in the coastal region of Southern California have introduced organic coffee intercropping in their well-established avocado orchards, and California coffee has grown in visibility and demand within the world's Specialty Coffee sector. The intercropping of coffee and avocados provides substantial environmental and economic potential for growers in California. For example, intercropping could lead to two valuable crop harvests on the same land while maintaining-or only slightly increasing-water application. Coffee-avocado intercropping has already brought positive results in terms of crop yield and quality. Notably, costal Southern California has developed into a region experiencing enormous urbanization pressure, therefore exposing the novel coffee-avocado intercropping practice to the unique set of challenges and opportunities of the peri-urban space.

Like many self-described pioneers, new coffee farmers in coastal California employ various approaches to sustainability, community development, and organic growing. All of these actions take place on historical landscapes that have experienced various forms of agricultural and urban or suburban development. California is a major breadbasket, fruit dish, and salad bowl while simultaneously becoming the most urbanized landscape in the country [11]. Scarcity (water, land, population pressures, restricted zoning) has imposed constraints but also foresight on growers, leading to new models of innovation and sustainability. Similar to other niche, high-end cultivars endemic to CA agriculture (i.e. wine, almonds), sustainable coffee is intricately linked to consumers interested in provenance, methods, and compelling stories connecting them to their food. This, too, is another integral part of what has become known as California Cuisine pioneered in the 1970s by Alice Waters. Growers espouse and practice various agrarian philosophies related to sustainability, community development, and organic growing. These farmers also face common challenges related to city and county zoning, other farmers, wine producers, citrus growers, and even residents with different visions of what CA landscapes should look like.

\section{Conclusion}

Through an informed understanding that farmland is not simply about producing food, new conversations can emerge between seemingly disparate stakeholders. Concepts like ecosystems services are becoming increasingly part of the public lexicon and educational efforts can help peri-urban communities understand and value the various benefits of their unique landscapes. Several layers of information, from historical assessment, landscape analyses, and direct observations, can provide tools to overcome barriers to collective dialog.

\section{References}

1. Curran Cournane F, Cain T, Greenhalgh S, Samarsinghe O (2016) Attitudes of farming communities towards urban growth and rural fragmentation - An Auckland case study. Land Use Policy 58(15): 241-250.

2. Allen A, da Silva NLA, Corubolo E (1999) Environmental problems and opportunities of the peri-urban interface and their impact upon the poor. Strategic Environmental Planning and Management for the PeriUrban Interface Research Project. The Development Planning Unit, UK.

3. Douglass I (1998) A regional network strategy for reciprocal ruralurban linkages. Third World Planning Review 4: 9-32.

4. Mann ML, Moritz MA, Batlori E, Baldwin JG, Gately CK, et al. (2014) Modeling residential development in California from 2000 to 2050: Integrating wildfire risk, wildland and agricultural encroachment. Land Use Policy 41: 438-452.

5. Renting H, Rossing WAH, Groot JCJ, Van Der Ploeg JD, Laurent C, et al. (2009) Exploring multifunctional agriculture. A review of conceptual approaches and prospects for an integrative transitional framework. Journal of Environmental Management 90(2): S112-S123.

6. (2014) US Department of Agriculture, National Agricultural Statistics Service. 2012 Census of Agriculture.

7. U.S. Census Bureau. QuickFacts: California; United States.

8. Krannich JM (2006) A modern disaster: Agricultural land, urban growth, and the need for a federally organized comprehensive land use planning model. Cornell Journal of Law and Public Policy 16(1).

9. Mead R, Willey RW (1980) The concept of a 'land equivalent ratio' and advantages in yields from intercropping. Experimental Agriculture 16(3): 217-228.

10.Zhang F, Li L (2003) Using competitive and facilitative interactions in intercropping systems enhances crop productivity and nutrient-use efficiency. Plant and Soil 248(1-2): 305-312.

11. Hise G, Deverell, WF (2000) Eden by Design: The 1930 OlmstedBartholomew Plan for the Los Angeles Region. Berkeley and Los Angeles: University of California Press, USA. 
(C) (P) This work is licensed under Creative

To Submit Your Article Click Here:

DOI: $10.32474 /$ CIACR.2019.06.000245

$\begin{gathered}\text { Current Investigations in Agriculture } \\ \text { and Current Research }\end{gathered}$
Assets of Publishing with us
- Global archiving of articles
- Immediate, unrestricted online access
- Rigorous Peer Review Process
- Authors Retain Copyrights
- Unique DOI for all articles

